\title{
Diabetes in older people: position statement of The Hong Kong Geriatrics Society and the Hong Kong Society of Endocrinology, Metabolism and Reproduction
}

\author{
CW Wong *, Jenny SW Lee, KF Tam, HF Hung, WY So, CK Shum, CY Lam, JN Cheng, SP Man, TW Auyeung
}

\begin{abstract}
A B S T R A C T
Following a survey on the clinical practice of geriatricians in the management of older people with diabetes and a study of hypoglycaemia in diabetic patients, a round-table discussion with geriatricians and endocrinologists was held in January 2015. Consensus was reached for six domains specifically related to older diabetic people: (1) the considerations when setting an individualised diabetic management; (2) inclusion of geriatric syndrome screening in assessment; (3) glycaemic and blood pressure targets; (4) pharmacotherapy; (5) restrictive diabetic diet; and (6) management goals for nursing home residents.
\end{abstract}

\section{Hong Kong Med J 2017;23:524-33 \\ DOI: 10.12809/hkmj166140}

${ }^{1}$ CW Wong *, FHKAM (Medicine), FHKCP

2 JSW Lee, FHKAM (Medicine), MD (CUHK)

\author{
${ }^{3}$ KF Tam, FHKAM (Medicine), FRCP (Edin, Glasg) \\ ${ }^{4}$ HF Hung, FHKAM (Medicine), FHKCP \\ ${ }^{5}$ WY So, FHKAM (Medicine), MD (CUHK) \\ ${ }^{6}$ CK Shum, FHKAM (Medicine), FHKCP \\ CY Lam, FHKAM (Medicine), FHKCP \\ 1 JN Cheng, FHKAM (Medicine), FHKCP \\ SP Man, FHKAM (Medicine), FHKCP \\ ${ }^{8}$ TW Auyeung, FHKAM (Medicine), MD (CUHK) \\ Department of Medicine and Geriatrics, Caritas Medical Centre, Sham \\ Shui Po, Hong Kong \\ Department of Medicine and Geriatrics, Tai Po Hospital, Tai Po, Hong \\ Kong \\ Department of Medicine, Hong Kong Buddhist Hospital, Lok Fu, Hong \\ Kong \\ 4 Department of Medicine and Geriatrics, Princess Margaret Hospital, Lai \\ Chi Kok, Hong Kong \\ ${ }^{5}$ Department of Medicine and Therapeutics, Prince of Wales Hospital, \\ Shatin, Hong Kong \\ ${ }^{6}$ Department of Medicine and Geriatrics, Tuen Mun Hospital, Tuen Mun, \\ Hong Kong \\ 7 Department of Medicine, Queen Elizabeth Hospital, Jordan, Hong Kong \\ ${ }^{8}$ Department of Medicine and Geriatrics, Pok Oi Hospital, Yuen Long, \\ Hong Kong \\ * Corresponding author: chitwaiwong@hotmail.com
}

\section{Introduction}

The prevalence of diabetes increases with age such that among the older population (age $\geq 65$ years), it was 6 times that of the younger population (age 18-64 years), reaching $21.4 \%$ in Hong Kong in 2004 to 2005. ${ }^{1}$ Although the prevalence among older people is quite constant over time, with an ageing population the number of older people with diabetes is expected to continuously increase in the future.

In addition to the increasing population of older diabetic people, heterogeneity among older people with varying levels of cognitive and functional ability, life expectancy, and social support present a challenge in clinical practice because there is no single treatment goal or management plan that can address all of the issues in this patient group. Recently, individualised and tailored care approaches to cater for the individual characteristics of older people have been promoted. ${ }^{2-7}$ Increasing attention to avoid treatment-related hypoglycaemia has also been emphasised. ${ }^{2-7}$ However, there is a gap in knowledge of the optimal management due to the paucity of clinical trials among older diabetic people, in particular those with frailty. This has led to a lack of consensus and variation of management in clinical practice.

A special interest group on diabetes mellitus, under the auspices of The Hong Kong Geriatrics Society (HKGS), has been established to raise the awareness of diabetes among older people; to address the special issues of older people associated with their varied physical, cognitive, and social needs; and to enhance their care. A survey on the opinions of local geriatricians about diabetes management in older people and data analysis of hypoglycaemia among diabetic patients in the local public sector were performed. A round-table discussion with geriatricians from the HKGS and endocrinologists from the Hong Kong Society of Endocrinology, Metabolism and Reproduction was then held on 24 January 2015. Discussion was based on evidence-based review of the current literature, scientific presentations by experts in the field, opinions from both geriatricians and endocrinologists, and the analysis of local data on hypoglycaemia of the diabetic patients. After the meeting, statements were drafted and circulated among the council members of HKGS and the Hong 
Kong Society of Endocrinology, Metabolism and Reproduction for comments. The final version was approved by all participants. The purpose of the round-table discussion was to arrive at a consensus on the management approach for older people with diabetes. This position statement was developed to serve as a reference for local clinicians.

\section{Survey on the clinical practice of geriatricians in the management of older people with diabetes}

An online survey was conducted to collect the opinions of geriatricians about the management of type 2 diabetes in older people between December 2014 and January 2015 (Appendix 1). The questionnaires were distributed to all 113 members of the HKGS. Approximately half (46.3\%) of the HKGS members returned the questionnaires. The following summarises the results of the questionnaire; details are shown in Appendix 2.

\section{Individualised diabetes management}

Most (60\%) of the respondents ranked risk of hypoglycaemia as the most important domain in setting an individualised diabetes management plan. Physical and mental functions, and co-morbidities and associated vascular diseases were also considered to be important.

\section{Geriatric syndromes}

Almost all of the respondents agreed that physical frailty (98\%) and cognitive impairment (96\%) should be assessed when managing older people with diabetes. More than $80 \%$ of respondents agreed that polypharmacy and nutritional problems should also be assessed.

\section{Target glycaemic and blood pressure control}

Respondents agreed that an individual's comorbidities, cognitive and functional status, and life expectancy must be considered when determining a glycaemic goal, such that more stringent control (target glycated haemoglobin [HbA1c] 6.5\%-7\%) should be considered for robust elderly people (59\% of respondents), less stringent control (target HbA1c 7\%-9\%) for those who are physically frail or cognitively impaired (52\%-57\% of respondents), and relaxed control (target $\mathrm{HbA} 1 \mathrm{c} \geq 9 \%$ ) for those receiving end-of-life care (50\% of respondents). Blood pressure targets set for older diabetic people were quite varied among the respondents; these ranged from $\leq 130 / 80 \mathrm{~mm} \mathrm{Hg}$ to $\leq 150 / 90 \mathrm{~mm} \mathrm{Hg}$ for robust elderly people, and $\leq 160 / 100 \mathrm{~mm} \mathrm{Hg}$ and avoidance of diastolic blood pressure of $<60 \mathrm{~mm} \mathrm{Hg}$ for those at the end of life.

\section{老年人的糖尿病：香港老年學會及香港內分泌 學會的立場聲明 \\ 王哲慧、李舜華、譚鉅富、孔憲輝、蘇詠儀、岑俊強、 \\ 林青儒、鄭晋毅、文兆彪、歐陽東偉}

根據老人科醫生「如何治理老年糖尿病病人」的問卷調查報告及對曾 經發生低血糖症的糖尿病患者進行的本地臨牀研究結果, 老人科醫 生及內分泌科醫生於 2015 年 1 月以圓桌會議形式就治理老年糖尿病病 人的事宜進行討論並達成共識。共識範疇如下：（1）為個別患者設 定度身訂造的糖尿病管理時需要考慮的事項；（2）將老年病綜合症 的篩查納入評估；（3）血糖和血壓指標；（4) 藥物治療；（5）糖 尿病飲食上的限制; 以及（6）對護老院內老年糖尿病患者的治療目 標。

\section{Pharmacotherapy}

The risk of hypoglycaemia was the most important concern for almost all the respondents (98\%) when prescribing glucose-lowering therapy. Dosing frequency was also a major concern $(76 \%$ of respondents). A vast majority (93\% of respondents) would prescribe metformin as the first-line glucoselowering therapy for robust elderly people, while a dipeptidyl peptidase-IV (DPP-IV) inhibitor (45\%) or sulphonylurea (45\%) was considered suitable for older people with organ failure or estimated glomerular filtration rate of $<30 \mathrm{~mL} / \mathrm{min}$, and metformin $(52 \%)$ and a DPP-IV inhibitor (34\%) was considered suitable for those at high risk of hypoglycaemia.

\section{Non-pharmacotherapy}

A majority $(>80 \%)$ of respondents considered that a restrictive diabetic diet should only be allocated for robust elderly people, but not for octogenarians, physically frail or cognitively impaired patients, and nursing home residents.

\section{Goals for nursing home residents}

Preventing hypoglycaemia was the goal of almost all the respondents (98\%). This was followed by preventing hospitalisation and avoiding acute metabolic complications (approximately 80\% of respondents).

\section{A study of hypoglycaemia in diabetic patients in Hong Kong}

A study of hypoglycaemia in the older diabetic population was performed. The study involved collection of data from the Clinical Data Analysis and Reporting System. Clinical data on diabetic people attending the accident and emergency department 
(AED) with the diagnosis of hypoglycaemia were collected. The study involved two parts: (1) analysis of all the AED attendance data on diabetic patients diagnosed with hypoglycaemia during the period between 1 July 2013 and 30 June 2014; and (2) subanalysis of data of diabetic patients attending the AED for hypoglycaemia from five hospitals (Alice Ho Miu Ling Nethersole Hospital, Caritas Medical Centre, Pok Oi Hospital, Queen Elizabeth Hospital, and Tuen Mun Hospital) during the period between 1 January 2014 and 31 January 2014.

Accident and emergency department visits for hypoglycaemia among diabetic patients in Hong Kong during a 1-year period between 1 July 2013 and 30 June 2014

A total of 2416 diabetic patients had attended all AEDs under the Hospital Authority in Hong Kong for hypoglycaemia between 1 July 2013 and 30 June 2014. The majority (78.2\%) of them were aged 65 years or older; $14.4 \%$ were from old-age homes, and the hospital admission rate was $81.1 \%$ (Table 1). Older patients ( $\geq 65$ years) had a significantly higher rate of hospital admission and 12-month mortality than patients younger than 65 years.

\section{Subanalysis of accident and emergency department visits for hypoglycaemia from five hospitals between 1 January 2014 and 31 January 2014}

Of the 133 diabetic patients included in the subanalysis, $105(78.9 \%)$ were older patients $(\geq 65$ years) [Table 2]. Tight glycaemic control with HbA1c of $\leq 7 \%$ was associated with a significantly higher 12 month mortality in older diabetic patients than those with less stringent control (27.8\% vs $11.8 \%$; $\mathrm{P}=0.04$ ). In addition, older patients with very tight glycaemic control (HbA1c $\leq 6 \%$ ) had a longer duration of stay in hospital than those with less stringent control (6.8 days vs 3.8 days; $\mathrm{P}=0.001)$. On the other hand, loose glycaemic control with $\mathrm{HbA} 1 \mathrm{c}$ of $\leq 8 \%$ and patients aged younger than 65 years were not associated with increased short-term (28-day readmission) and long-term (12-month mortality) adverse outcomes. Multivariate analysis showed that male sex, higher Charlson Comorbidity Index score, dementia, and lower HbA1c level were independent predictors for 12-month mortality among the older diabetic patients (Table 3 ).

\section{Factors to be considered in the management of older people with type 2 diabetes mellitus}

\section{Hypoglycaemic risk}

Advanced age is an independent risk factor for hypoglycaemia. ${ }^{8}$ Older people are intrinsically prone to hypoglycaemia. With increasing age, hypoglycaemic warning symptoms become less intense and hypoglycaemic unawareness becomes more common even with intact physiological glucose counter-regulatory response (ie decreased insulin

TABLE I. Accident and emergency department attendance for hypoglycaemia among diabetic patients in Hong Kong from I July 2013 to 30 June 2014

\begin{tabular}{|c|c|c|c|c|}
\hline \multirow[t]{2}{*}{ Variable } & \multicolumn{3}{|c|}{ No. $(\%)$ of patients or mean \pm SD (range) } & \multirow[t]{2}{*}{ P valuet } \\
\hline & All ages $(n=2416)$ & Age $<65$ years $(n=526)$ & Age $\geq 65$ years $\left(n=1890^{\star}\right)$ & \\
\hline Female & $1293(53.5)$ & $213(40.5)$ & $1080(57.1)$ & $<0.001$ \\
\hline Age (years) & $73.4 \pm 13.2(18-101)$ & $53.5 \pm 10.5(18-64)$ & $78.9 \pm 7.1(65-101)$ & - \\
\hline Admission from $\mathrm{OAH}$ & $348(14.4)$ & $29(5.5)$ & $319(16.9)$ & $<0.001$ \\
\hline Admission to ward & 1949 (81.1) & $355(67.5)$ & $1594(84.3)$ & $<0.001$ \\
\hline LOS (days) & $4.7 \pm 7.0$ & $4.4 \pm 6.7$ & $4.7 \pm 7.0$ & 0.45 \\
\hline 28-Day readmission & $528(27.1)$ & $94(26.4)$ & $434(23.0)$ & 0.82 \\
\hline Discharge status & & & & $<0.001$ \\
\hline Death & $56(2.9)$ & $6(1.7)$ & $50(3.1)$ & \\
\hline Home & $1697(87.1)$ & $309(88.7)$ & $1388(87.1)$ & \\
\hline Convalescence & $141(7.2)$ & $14(3.9)$ & $127(8.0)$ & \\
\hline DAMA & $47(2.4)$ & $24(6.8)$ & $23(1.4)$ & \\
\hline Others & $8(0.4)$ & $2(0.6)$ & $6(0.4)$ & \\
\hline 12-Month mortality $\ddagger$ & $395(16.3)$ & $35(6.7)$ & $360(19.0)$ & $<0.001$ \\
\hline
\end{tabular}

Abbreviations: DAMA = discharge against medical advice; $L O S=$ length of stay; $N A=$ not applicable; $O A H=$ old-age home; $S D=$ standard deviation

* $78.2 \%$ Of all adult patients

† Comparison of clinical characteristics between age $<65$ years and age $\geq 65$ years was performed by Student's $t$ test

‡ Up to 15 January 2015 
TABLE 2. Comparison of adverse outcomes of older diabetic patients ( $\geq 65$ years) who presented to five accident and emergency departments with hypoglycaemia according to different glycated haemoglobin values between I January 2014 and 3 I January 20 I4*

\begin{tabular}{|c|c|c|c|c|c|c|c|c|c|c|}
\hline \multirow[t]{2}{*}{ Variable } & \multirow[t]{2}{*}{ All } & \multicolumn{9}{|c|}{ HbA1c (\%)† } \\
\hline & & $\leq 6$ & $>6$ & $P$ value & $\leq 7$ & $>7$ & $P$ value & $\leq 8$ & $>8$ & $P$ value \\
\hline Age $\geq 65$ years & 105 & $18(17 \ddagger)$ & $87(79 \ddagger)$ & - & $54(49 \ddagger)$ & $51(47 \ddagger)$ & - & $81(74 \ddagger)$ & $24(22 \ddagger)$ & - \\
\hline LOS (days) & $4.3 \pm 5.7$ & $6.8 \pm 5.9$ & $3.8 \pm 5.5$ & 0.001 & $4.6 \pm 5.5$ & $4.1 \pm 5.8$ & 0.65 & $4.3 \pm 5.8$ & $4.3 \pm 5.3$ & 0.61 \\
\hline 28-Day readmission§ & 31 & $5(27.8 \%)$ & $26(29.9 \%)$ & 1.00 & $14(25.9 \%)$ & $17(33.3 \%)$ & 0.41 & $22(27.2 \%)$ & $9(37.5 \%)$ & 0.33 \\
\hline 12-Month mortality & 21 & $8(44.4 \%)$ & $13(14.9 \%)$ & 0.01 & $15(27.8 \%)$ & $6(11.8 \%)$ & 0.04 & $16(19.8 \%)$ & $5(20.8 \%)$ & 1.00 \\
\hline Age $<65$ years & 28 & $3(1 \ddagger)$ & $25(19 \ddagger)$ & - & $7(5 \ddagger)$ & $21(15 \ddagger)$ & - & $15(11 \ddagger)$ & $13(9 \ddagger)$ & - \\
\hline LOS (days) & $4.4 \pm 4.1$ & - & $4.3 \pm 4.2$ & - & $4.6 \pm 2.4$ & $4.3 \pm 4.6$ & 0.31 & $3.9 \pm 2.5$ & $4.9 \pm 5.6$ & 0.66 \\
\hline 28-Day readmission§ & 7 & $1(33.3 \%)$ & $6(24.0 \%)$ & 1.00 & $2(28.6 \%)$ & $5(23.8 \%)$ & 1.00 & $5(33.3 \%)$ & $2(15.4 \%)$ & 0.40 \\
\hline 12-Month mortality & 5 & 0 & $2(8.0 \%)$ & 1.00 & $2(28.6 \%)$ & $3(14.3 \%)$ & 0.57 & $3(20 \%)$ & $2(15.4 \%)$ & 1.00 \\
\hline
\end{tabular}

Abbreviations: $\mathrm{HbAIc}=$ glycated haemoglobin; $\mathrm{LOS}=$ length of stay

* The five hospitals were Alice Ho Miu Ling Nethersole Hospital, Caritas Medical Centre, Pok Oi Hospital, Queen Elizabeth Hospital, and Tuen Mun Hospital; comparison of adverse outcomes was performed by Student's $t$ test

+ Data are shown as No. of patients, No. (\%) of patients, or mean \pm standard deviation

‡ No. of patients who were admitted to a ward

$\S$ Emergency readmission to hospital within 28 days of discharge

TABLE 3. Multivariate analysis of 12 -month mortality among the older diabetic patients ( $\geq 65$ years) following the index AED attendance $(n=105) * \dagger$

\begin{tabular}{lccr}
\hline & Odds ratio & P value & 95\% Confidence interval \\
\hline Male sex & 15.51 & 0.004 & $2.42-99.15$ \\
$\mathrm{HbA1c}$ & 0.40 & 0.01 & $0.19-0.83$ \\
$\mathrm{CCl}$ & 1.82 & 0.02 & $1.08-3.05$ \\
Dementia & 10.89 & 0.01 & $1.88-63.14$ \\
\hline
\end{tabular}

Abbreviations: $\mathrm{AED}=$ accident and emergency department; $\mathrm{CCl}=$ Charlson Comorbidity Index; $\mathrm{Cl}=$ confidence interval; $\mathrm{HbA} \mathrm{l}$ c $=$ glycated haemoglobin

* Logistic regression model was used in multivariate analysis to identify risk factors for 12-month mortality

+ Adjusted for age, hypertension, renal insufficiency, and 28-day readmission following the index AED attendance

secretion, and increased glucagon and epinephrine secretion). ${ }^{9-12}$ Furthermore, the physiologically higher blood glucose level for the initiation of neurogenic warning symptoms (eg palpitation, tremor, and sweating - the result of automonic activation) than that for onset of neuroglycopenic symptoms (eg confusion, seizure, and loss of consciousness-the result of brain glucose deprivation), which allows time to take measures to avoid neuroglycopenia and severe hypoglycaemia, tends to be lost in the older people. ${ }^{12}$ The impaired perception of the warning symptoms of hypoglycaemia and the narrower or even absence of a glycaemic threshold gap between the development of neurogenic and neuroglycopenic symptoms put elderly people at a high risk for severe hypoglycaemia.

Furthermore, with a longer duration of type 2 diabetes and subsequent progression to endogenous insulin deficiency, counter-regulatory responses to hypoglycaemia are compromised. Additionally, the neurogenic warning symptoms become attenuated and lead to hypoglycaemic unawareness. Compromised glucose counter-regulation and hypoglycaemia unawareness increase the risk of severe iatrogenic hypoglycaemia by 25 -fold and 6-fold, respectively. ${ }^{13,14}$ Multiple co-morbidities, polypharmacy, and cognitive dysfunction associated with advancing age are also risk factors for hypoglycaemia (see below).

\section{Geriatric syndromes}

Diabetes predisposes older people to the development of geriatric syndromes as it is associated with risk for dementia, depression, polypharmacy, fall and fracture, urinary incontinence, visual impairment, and chronic pain. The presence of geriatric syndromes is linked with functional decline and increasing frailty that would limit a patient's functional independence and complicate medical management. Early recognition and including geriatric syndromes in the management plan are recommended. 


\section{Cognitive dysfunction}

Patients with diabetes are at increased risk for dementia. They have been shown to have a 1.2- to 1.5-fold higher rate of decline in cognitive function than those without diabetes, ${ }^{15}$ and were at a higher risk for developing Alzheimer's disease and vascular dementia by approximately 1.5 -fold and 2.5-fold, respectively. ${ }^{16}$ Additionally, adverse effect of treatment-related hypoglycaemia, especially if it is severe, has been shown to be associated with subsequent dementia in older diabetic patients. ${ }^{17-19}$ There was also a graded increase in dementia risk with the number of severe hypoglycaemic episodes experienced, such that the risk was almost double for three or more episodes when compared with only one episode. ${ }^{17}$ Furthermore, there is a bidirectional association of hypoglycaemia with dementia in which hypoglycaemia damages the brain and that, in turn, decreases one's ability to manage diabetes or recognise hypoglycaemic symptoms leading to the subsequent risk of hypoglycaemia, that further impairs cognitive function in a vicious cycle. ${ }^{20}$

\section{Depression}

A systematic review and meta-analysis found people with type 2 diabetes had a $24 \%$ increased risk of developing depression. ${ }^{21}$ On the other hand, depression was associated with a $60 \%$ increased risk of type 2 diabetes in another systematic review. ${ }^{22}$ Despite the fact that depression in diabetic patients is common, it is often undiagnosed and untreated..$^{23}$ Like cognitive dysfunction, depression may impede functionality and diabetic self-management causing erratic timing of medication intake, irregular eating, inability to self-monitor blood glucose, and failure to recognise hypoglycaemic symptoms to enable prompt management. These may worsen glycaemic control and increase the risk of diabetic and treatment-related complications. Early detection of depression, especially in those with unexplained decline in clinical status, is warranted..$^{24}$

\section{Polypharmacy}

Medications prescribed for co-morbidities predispose patients to the impact of polypharmacy. Because of the age-related changes in pharmacokinetics and pharmacodynamics, the adverse effects of drugs and drug-drug interactions are further exacerbated in older patients. Older diabetic patients using four or more concomitant medications have been found to be at increased risk for developing serious hypoglycaemia..$^{8,25}$ Polypharmacy can also precipitate geriatric syndromes such as fall, cognitive impairment, urinary incontinence, and malnutrition. ${ }^{26,27}$

\section{Fall and fracture}

Diabetic complications (such as autonomic dysfunction with orthostatic hypotension, peripheral neuropathy with gait disorder, and diabetic retinopathy with poor vision) ${ }^{28}$ and treatment complications (such as metforminassociated vitamin $B_{12}$ deficiency with resultant neuropathy $)^{29}$ increase the susceptibility of diabetic patients to fall. Besides, diabetes has been shown to be an independent risk factor for fracture..$^{30}$ Patients who have longer diabetes duration, suboptimal glucose control, diabetic retinopathy, insulin use or thiazolidinedione use in women, and increased risk for fall are particularly at high risk for fracture. ${ }^{30-32}$

\section{Chronic pain and urinary incontinence}

Neuropathic pain affects up to one third of patients with diabetes and is more prevalent in women. ${ }^{33}$ Its occurrence may not relate to the severity of neuropathy and may even occur in patients without clinical neuropathy. Besides, pain from other sources such as bone, joint, and back is common in older people. Urinary incontinence is also common in diabetic patients, especially women. Up to one third of female patients with diabetes had reported incontinence at least weekly in a survey in which urge incontinence was associated with advancing age. ${ }^{34}$ Managing treatable causes such as urinary tract infection, faecal impaction, use of offensive medications, and poor glycaemic control with polyuria may alleviate incontinence. ${ }^{24}$ Both pain and urinary incontinence are often neglected in clinical practice and may lead to adverse outcomes such as anxiety, depression, decreased socialisation, fall and fracture if left untreated. ${ }^{35-37}$

\section{Co-morbidities and other cardiovascular risk factors}

As many as $40 \%$ of older people with diabetes have four or more chronic conditions. ${ }^{38}$ Multiple comorbidities may have profound effects on patients' ability to self-care. Additionally, the level of comorbidities affects treatment outcomes. Diabetic patients with low-to-moderate co-morbidity have been found to have a lower incidence of cardiovascular events than those with high co-morbidity, even with comparable HbA1c levels. ${ }^{39}$ Furthermore, comorbidity, especially renal impairment, hepatic disease and cognitive dysfunction increase the risk of severe hypoglycaemia, ${ }^{25}$ which is associated with twice the risk of cardiovascular disease (myocardial infarction, congestive heart failure, stroke, and cardiovascular death) in diabetic patients..$^{40}$ Diabetic patients with concomitant coronary artery disease who experience hypoglycaemia are particularly prone to ischaemic heart attack. ${ }^{41}$ These have clinical implications - in patients with multiple comorbidities, intensive glucose treatment may not be beneficial, but might make patients prone to treatment-related hypoglycaemia which, in turn, 
may exacerbate the cardiovascular event, especially in those at risk for cardiovascular disease.

Management of other cardiovascular factors to lower the cardiovascular risk is also important. Systolic blood pressure (SBP) of $\geq 140 \mathrm{~mm} \mathrm{Hg}$ increases the risk of cardiovascular events, whereas lowering blood pressure from a high level reduces both cardiovascular and microvascular complications in older diabetic patients. ${ }^{42-44}$ There is no further benefit to lowering SBP to $<130 \mathrm{~mm} \mathrm{Hg}$ however, as compared to SBP of $130-140 \mathrm{~mm} \mathrm{Hg}$, but may increase mortality. ${ }^{45,46}$ Furthermore, a low diastolic blood pressure of $<70 \mathrm{~mm} \mathrm{Hg}$ that may result from SBP reduction is associated with higher cardiovascular disease risk. ${ }^{42}$ Thus, the recommended target blood pressure for older diabetic patients is $<140 / 90 \mathrm{~mm} \mathrm{Hg}$, if tolerated. ${ }^{2}$

Lipid lowering by statins has been shown to reduce the incidents of major vascular events by approximately $20 \%$ per $\mathrm{mmol} / \mathrm{L}$ low-density lipoprotein cholesterol reduction in diabetic patients and in patients age $\geq 65$ years. ${ }^{47}$ This benefit emerges quite rapidly, within 1 to 2 years of treatment, suggesting that most older people could benefit from statins except for those with very limited life expectancy. There is limited evidence with drugs other than statins for reduction of cardiovascular risk.

\section{Is stringent glycaemic control beneficial?}

The UKPDS (UK Prospective Diabetes Study) that recruited patients with newly diagnosed type 2 diabetes (mean age, 53 years) showed a $25 \%$ risk reduction in microvascular complications in the intensive-therapy group (HbA1c achieved, 7\%) after a median follow-up of 11 years. ${ }^{48}$ Macrovascular benefit, in terms of a $15 \%$ risk reduction for myocardial infarction, emerged only during 10 years of extended post-trial follow-up. ${ }^{49}$ In three more recent large-scale trials-ACCORD (Action to Control Cardiovascular Risk in Diabetes), ADVANCE (Action in Diabetes and Vascular Disease: Preterax and Diamicron Modified Release Controlled Evaluation), and VADT (Veterans Affairs Diabetes Trial) - which recruited older people (mean age, 60-66 years) with type 2 diabetes duration of 8 to 11.5 years and of whom $32 \%$ to $40 \%$ had a history of cardiovascular events, the intensive-therapy group (HbA1c achieved, 6.4\%-6.9\%) showed no benefit in the reduction of overall major cardiovascular events and death over 5 years of follow-up but only a lower rate of non-fatal myocardial infarction in the ACCORD trial. ${ }^{50-53}$ Instead, there was higher mortality in the intensive-therapy group of the ACCORD trial that led to premature discontinuation of intensive therapy after 3.5 years of follow-up. For the microvascular outcomes, the intensivetherapy group had lowered macroalbuminuria by
$30 \%$, decreased progression of retinopathy by $33 \%$, and a modest risk reduction in the development of peripheral neuropathy. ${ }^{51,54,55}$ All of these trials revealed that intensive therapy was associated with a higher rate of hypoglycaemic episodes, with up to 2- to 3-fold increase in severe hypoglycaemia. The findings imply that good glycaemic control is most beneficial if it commences earlier, before the establishment of long-term complications. Furthermore, it takes time for intensive glycaemic control to reap microvascular benefit (over 5 years) and even longer for macrovascular benefit (over 10-20 years). ${ }^{48,49,51,52,54,55}$ For patients with limited life expectancy and multiple co-morbidities, the adverse effects are likely to outweigh the benefits.

\section{Individualised approach}

The primary aim of diabetes management is to optimise glycaemic control to avoid acute hyperglycaemia complications and prevent longterm diabetic complications, both microvascular and macrovascular, and to minimise the adverse effect of treatment-related hypoglycaemia. Given the heterogeneous health status of older people, diabetes intervention strategies designed for long-term benefits may not be appropriate for all older people. A patient-centred approach for diabetes management that takes account of the potential benefits and risks of treatment, health and functional state, and social background for an individual patient has been increasingly emphasised. Accordingly, various frameworks or guidelines have been developed to assist in determining glycaemic treatment goals in older diabetic patients. ${ }^{2-6}$ In general, for older people who are relatively young, healthy and active, the same glycaemic target as for young people may be worthwhile to prevent long-term complications. For frail older people with multiple co-morbidities and limited life expectancy, the aim of glycaemic control is to prevent acute hyperglycaemic complications (polyuria, dehydration, hyperglycaemic hyperosmolar syndrome, infection, and poor wound healing) while avoiding treatment adverse effects, rather than to gain long-term benefit. The suggested target HbA1c varies from $7.0 \%$ to $7.5 \%$ for healthy older people to $8 \%$ to $9 \%$ for those who are in very poor health. ${ }^{2-6}$ The choice of anti-glycaemic agents should focus on safety, with low risk for hypoglycaemia, and metformin is generally considered to be the first-line therapy for older people. ${ }^{2-6}$ Avoidance of drugs with potential adverse effects that may exacerbate underlying conditions such as heart failure, osteoporosis with risk of fracture, and renal dysfunction is also advised.

\section{Restrictive diabetic diet}

Because of altered taste and smell, anorexia of ageing, difficulty in swallowing, and decreased functional 
state, food intake tends to decline with advancing age. A restrictive diet for glycaemic control that is designed for young and middle-aged diabetic patients may not be suitable for all older diabetic patients. ${ }^{56}$ Instead, a restrictive diet may limit the variety and flavour of food offered, which may exacerbate poor food intake leading to unintentional weight loss and undernutrition. Those who are frail, institutionalised, or underweight are particularly at risk, with increased morbidity and mortality. ${ }^{57}$ Thus, a less restrictive diet or even a liberal diet with modification of medications to control blood glucose may be advisable for susceptible patients. ${ }^{58}$ Nutritional assessment taking account of a patient's circumstances to guide individual nutritional intervention is advocated.

\section{Consensus statement for the management of older people with diabetes}

After the round-table discussion, consensus was reached on the following six domains to address the management of older diabetic people:

(1) When setting an individualised glycaemic goal, the important considerations should include:

(a) risk of hypoglycaemia;

(b) physical and mental function;

(c) co-morbidities and associated vascular disease; and

(d) family support and community resources.

(2) In view of the high risk of the associated comorbidities with functional and cognitive impairment, use of an extended diabetic complication screening tool to include the geriatric syndromes is recommended. Other important reasons for screening include the close association of geriatric syndromes with diabetes, implications for choosing therapeutic interventions, and the considerable impact on quality of life. Common syndromes that could be included are:
(a) frailty;
(b) cognitive dysfunction;
(c) polypharmacy;
(d) nutrition;
(e) falls;
(f) hearing, visual impairment;
(g) depression;
(h) pain; and
(i) urinary incontinence.

(3) Because of the heterogeneous health status of older people, glucose and blood pressure targets should be individualised. An important consideration would be whether the time frame of potential benefits from treatment in longterm clinical trials is within the life expectancy of an individual patient: (a) glycaemic target:

(i) HbA1c goal similar to that of general adults, but without excessive hypoglycaemia, should be considered for robust elderly people;

(ii) higher HbA1c up to $8.5 \%$ can be considered for those who are physically and cognitively frail or in nursing homes; and

(iii) liberal HbA1c without setting a target, aiming at symptomatic control, for those at the end of life.

(NB: HbA1c level would be potentially influenced by co-morbidities such as anaemia, which is more prevalent in older adults.)

(b) blood pressure target:

(i) similar to general adults $(\leq 140 / 90 \mathrm{~mm} \mathrm{Hg})$ for robust elderly people;

(ii) $\leq 150 / 90 \mathrm{~mm} \mathrm{Hg}$ for physically or cognitively frail elderly people, with avoidance of hypotension; and

(iii) liberal without setting a target for those at the end of life.

(4) In view of the risk of polypharmacy and the age-related changes in pharmacokinetics and pharmacodynamics, the following points need to be noted:

(a) when prescribing glucose-lowering agent(s), the major considerations should include:

(i) risk of hypoglycaemia;

(ii) dosing frequency and complexity of drug regimen;

(iii) tolerability and adverse effects such as gastrointestinal intolerance, change in fluid status, heart failure, fracture risk, weight change, and risk of urogenital infection;

(iv) glucose-lowering effect; and

(v) overall health status and quality of life of the patient.

(b) Choice of drugs:

(i) Metformin is generally chosen as a first-line agent because of robust clinical efficacy and low risk of hypoglycaemia. Its use is mainly limited by gastrointestinal tolerability, renal insufficiency, risk of lactic acidosis, and subclinical vitamin $\mathrm{B}_{12}$ deficiency.

(ii) Sulphonylureas are of low cost with high anti-glycaemic efficacy. However, they are associated with higher risk of hypoglycaemia and should be used with caution in older people. A long-acting sulphonylurea such as glibenclamide should be avoided because of the high incidence of prolonged hypoglycaemia 
and possibly increased mortality.

(iii) DPP-IV inhibitors have a low hypoglycaemia risk, modest clinical efficacy, good tolerability, and convenient dosing. The disadvantage is their higher cost.

(iv) Thiazolidinediones have low hypoglycaemia risk, and good efficacy and durability. The adverse effects include fluid retention, weight gain, and increased fractures. Lower doses are generally better tolerated.

(v) Sodium-glucose cotransporter 2 inhibitors have low hypoglycaemia risk, with decreased body weight, and modest clinical efficacy with some favourable cardiovascular safety data. Adverse effects include urogenital infection, urinary frequency, and dehydration. There may also be reduction of blood pressure so dose adjustment of any anti-hypertensive agent may be needed. They are of a higher cost with limited efficacy in patients with impaired renal function.

(vi) Alpha-glucosidase inhibitors have modest anti-glycaemic efficacy and low hypoglycaemic risk. Adverse effects include bloating, flatulence, and diarrhoea.

(vii) Glucagon-like peptide 1 agonists have low hypoglycaemia risk and good antiglycaemic efficacy with associated weight loss. The disadvantages are the high cost; the need for injections; and adverse effects of nausea, vomiting, and anorexia.

(viii) Insulins are highly effective in lowering glucose with various regimens. They are associated with significant hypoglycaemic risk and weight gain. The requirement for a high level of self-management education may be difficult for older people with physical or mental disabilities.

(5) A restrictive (therapeutic) diabetic diet may not be beneficial for some elderly diabetic people and may lead to decreased intake, unintentional weight loss, and undernutrition. Individualised nutritional approaches addressing personal food preferences and goals with a wider variety of food choices should be adopted. This is particularly applicable to those who are:
(a) >80 years old;
(b) physically frail;
(c) cognitively frail;
(d) underweight; and
(e) nursing home residents.

(6) Nursing home residents are distinct from community-dwelling older people because they are generally more frail with co-morbidities requiring high levels of care. The staff at longterm care facilities should be offered appropriate education and training in diabetes. The management of elderly nursing home residents with diabetes should aim to:

(a) prevent hypoglycaemia;

(b) prevent hospitalisation;

(c) avoid acute metabolic complications; and

(d) provide timely end-of-life care and advance care planning.

\section{Conclusion}

With the increasing population of older people with diabetes and the complexity and heterogeneity of older people, it is time to change our clinical practice in managing diabetes in older peoplemanagement should not be solely based on the clinical guidance for younger people with diabetes. We need to consider the course of the disease in the context of individual characteristics (co-morbidities, frailty, cognitive impairment, life expectancy, risk of treatment-induced hypoglycaemia, patients' attitudes, social support, etc) to tailor a treatment goal and management plan. This approach has recently been advocated by several international organisations such as the American Diabetes Association and the American Geriatrics Society. Our consensus statement takes the initiative in promoting better diabetes care for older people in our locality. The guidance takes into consideration of local experience to address issues specifically related to older diabetic people, such as the inclusion of a comprehensive geriatric assessment to screen for geriatric syndromes and psychosocial needs, which is often missed in a busy clinic, and the glycaemic targets for broadly classified groups of patients, which could guide clinicians in daily practice. Nonetheless, the consensus statement is far from complete in addressing all the issues-the details on how to implement the geriatric assessment for optimal therapy, the appropriate treatment goals for all the multifaceted scenarios of older people, the optimal level of blood pressure control, and the allocation of social support for care in the community and much more, remain to be determined.

\section{Appendices}

Additional material related to this article can be found on the HKMJ website. Please go to <http:// www.hkmj.org > , and search for the article.

\section{Declaration}

All authors have disclosed no conflicts of interest. 


\section{References}

1. McGhee SM, Cheung WL, Woo J, et al. Trends of disease burden consequent to diabetes in older persons in Hong Kong: implications of population ageing. Hong Kong SAR: Hong Kong Jockey Club; 2009.

2. American Geriatrics Society Expert Panel on Care of Older Adults with Diabetes Mellitus, Moreno G, Mangione CM, Kimbro L, Vaisberg E. Guidelines abstracted from the American Geriatrics Society Guidelines for Improving the Care of Older Adults with Diabetes Mellitus: 2013 update. J Am Geriatr Soc 2013;61:2020-6.

3. Ismail-Beigi F, Moghissi E, Tiktin M, Hirsch IB, Inzucchi $\mathrm{SE}$, Genuth S. Individualizing glycemic targets in type 2 diabetes mellitus: implications of recent clinical trials. Ann Intern Med 2011;154:554-9.

4. Sinclair A, Morley JE, Rodriguez-Mañas L, et al. Diabetes mellitus in older people: position statement on behalf of the International Association of Gerontology and Geriatrics (IAGG), the European Diabetes Working Party for Older People (EDWPOP), and the International Task Force of Experts in Diabetes. J Am Med Dir Assoc 2012;13:497-502.

5. Inzucchi SE, Bergenstal RM, Buse JB, et al. Management of hyperglycemia in type 2 diabetes: a patient-centered approach: position statement of the American Diabetes Association (ADA) and the European Association for the Study of Diabetes (EASD). Diabetes Care 2012;35:1364-79.

6. Kirkman MS, Briscoe VJ, Clark N, et al. Diabetes in older adults: a consensus report. J Am Geriatr Soc 2012;60:234256.

7. Inzucchi SE, Bergenstal RM, Buse JB, et al. Management of hyperglycemia in type 2 diabetes, 2015: A patient-centered approach: update to a position statement of American Diabetes Association and the European Association for the Study of Diabetes. Diabetes Care 2015;38:140-9.

8. Shorr RI, Ray WA, Daugherty JR, Griffin MR. Incidence and risk factors for serious hypoglycemia in older persons using insulin or sulfonylureas. Arch Intern Med 1997;157:1681-6.

9. Bremer JP, Jauch-Chara K, Hallschmid M, Schmid S, Schultes B. Hypoglycemia unawareness in older compared with middle-aged patients with type 2 diabetes. Diabetes Care 2009;32:1513-7.

10. Brierley EJ, Broughton DL, James OF, Alberti KG. Reduced awareness of hypoglycaemia in the elderly despite an intact counter-regulatory response. QJM 1995;88:439-45.

11. Meneilly GS, Cheung E, Tuokko H. Altered responses to hypoglycemia of healthy elderly people. J Clin Endocrinol Metab 1994;78:1341-8.

12. Matyka K, Evans M, Lomas J, Cranston I, Macdonald I, Amiel SA. Altered hierarchy of protective responses against severe hypoglycemia in normal aging in healthy men. Diabetes Care 1997;20:135-41.

13. White NH, Skor DA, Cryer PE, Levandoski LA, Bier DM, Santiago JV. Identification of type I diabetic patients at increased risk for hypoglycemia during intensive therapy. N Engl J Med 1983;308:485-91.

14. Gold AE, Macleod KM, Frier BM, Frequency of severe hypoglycemia in patients with type I diabetes with impaired awareness of hypoglycemia. Diabetes Care 1994;17:697-703.

15. Cukierman T, Gerstein HC, Williamson JD. Cognitive decline and dementia in diabetes-systematic overview of prospective observational studies. Diabetologia 2005;48:2460-9.
16. Lu FP, Lin KP, Kuo HK. Diabetes and the risk of multisystem aging phenotypes: a systematic review and metaanalysis. PLoS One 2009;4:e4144.

17. Whitmer RA, Karter AJ, Yaffe K, Quesenberry CP Jr, Selby JV. Hypoglycemic episodes and risk of dementia in older patients with type 2 diabetes mellitus. JAMA 2009;301:1565-72.

18. Lin $\mathrm{CH}$, Sheu WH. Hypoglycaemic episodes and risk of dementia in diabetes mellitus: 7-year follow-up study. J Intern Med 2013;273:102-10.

19. Aung PP, Strachan MW, Frier BM, et al. Severe hypoglycaemia and late-life cognitive ability in older people with type 2 diabetes: the Edinburgh Type 2 Diabetes Study. Diabet Med 2012;29:328-36.

20. Yaffe K, Falvey CM, Hamilton $N$, et al. Association between hypoglycemia and dementia in a biracial cohort of older adults with diabetes mellitus. JAMA Intern Med 2013;173:1300-6.

21. Nouwen A, Winkley K, Twisk J, et al. Type 2 diabetes mellitus as a risk factor for the onset of depression: a systematic review and meta-analysis. Diabetologia 2010;53:2480-6.

22. Mezuk B, Eaton WW, Albrecht S, Golden SH. Depression and type 2 diabetes over the lifespan: a meta-analysis. Diabetes Care 2008;31:2383-90.

23. Li C, Ford ES, Zhao G, Ahluwalia IB, Pearson WS, Mokdad AH. Prevalence and correlates of undiagnosed depression among U.S. adults with diabetes: the Behavioral Risk Factor Surveillance System, 2006. Diabetes Res Clin Pract 2009;83:268-79.

24. Brown AF, Mangione CM, Saliba D, Sarkisian CA; California Healthcare Foundation/American Geriatrics Society Panel on Improving Care for Elders with Diabetes. Guidelines for improving the care of the older person with diabetes mellitus. J Am Geriatr Soc 2003;51(5 Suppl Guidelines):S265-80.

25. Holstein A, Plaschke A, Egberts EH. Clinical characterisation of severe hypoglycaemia-a prospective population-based study. Exp Clin Endocrinol Diabetes 2003;111:364-9.

26. Huang ES, Karter AJ, Danielson KK, Warton EM, Ahmed AT. The association between the number of prescription medications and incident falls in a multi-ethnic population of adult type- 2 diabetes patients: the diabetes and aging study. J Gen Intern Med 2010;25:141-6.

27. Maher RL, Hanlon J, Hajjar ER. Clinical consequences of polypharmacy in elderly. Expert Opin Drug Saf 2014;13:5765.

28. Mayne D, Stout NR, Aspray TJ. Diabetes, falls and fractures. Age Ageing 2010;39:522-5.

29. Bauman WA, Shaw S, Jayatilleke E, Spungen AM, Herbert $\mathrm{V}$. Increase intake of calcium reverses vitamin B12 malabsorption induced by metformin. Diabetes Care 2000;23:1227-31.

30. Schneider AL, Williams EK, Brancati FL, Blecker S, Coresh J, Selvin E. Diabetes and risk of fracture-related hospitalization: the Atherosclerosis Risk in Communities Study. Diabetes Care 2013;36:1153-8.

31. Loke YK, Singh S, Furberg CD. Long-term use of thiazolidinediones and fractures in type 2 diabetes: a metaanalysis. CMAJ 2009;180:32-9.

32. Ivers RQ, Cumming RG, Mitchell P, Peduto AJ; Blue Mountains Eye Study. Diabetes and risk of fracture: The 
Blue Mountains Eye Study. Diabetes Care 2001;24:1198203.

33. Abbott CA, Malik RA, van Ross ER, Kulkarni J, Boulton AJ. Prevalence and characteristics of painful diabetic neuropathy in a large community-based diabetic population in the U.K. Daibetes Care 2011;34:2220-4.

34. Brown JS, Vittinghoff E, Lin F, Nyberg LM, Kusek JW, Kanaya AM. Prevalence and risk factors for urinary incontinence in women with type 2 diabetes and impaired fasting glucose: findings from the National Health and Nutrition Examination Survey (NHANES) 2001-2002. Diabetes Care 2006;29:1307-12.

35. AGS Panel on Persistent Pain in Older Persons. The management of persistent pain in older persons. J Am Geriatr Soc 2002;50(6 Suppl):S205-24.

36. Brown JS, Vittinghoff E, Wyman JF, et al. Urinary incontinence: does it increase risk for falls and fracture? J Am Geriatr Soc 2000;48:721-5.

37. Dugan E, Cohen SJ, Bland DR, et al. The association of depressive symptoms and urinary incontinence among older adults. J Am Geriatr Soc 2000:48:413-6.

38. Wolff JL, Starfield B, Anderson G. Prevalence, expenditures, and complications of multiple chronic conditions in the elderly. Arch Intern Med 2002;162:2269-76.

39. Greenfield S, Billmek J, Pellegrini F, et al. Comorbidity affects the relationship between glycemic control and cardiovascular outcomes in diabetes: a cohort study. Ann Intern Med 2009;151:854-60.

40. Goto A, Arah OA, Goto M, Terauchi Y, Noda M. Severe hypoglycaemia and cardiovascular disease: systematic review and meta-analysis with bias analysis. BMJ 2013;347:f4533.

41. Desouza C, Salazar H, Cheong B, Murgo J, Fonseca V. Association of hypoglycemia and cardiac ischemia: a study based on continuous monitoring. Diabetes Care 2003;26:1485-9.

42. Anderson RJ, Bahn GD, Moritz TE, et al. Blood pressure and cardiovascular disease risk in the Veterans Affairs Diabetes Trial. Diabetes Care 2011;34:34-8.

43. Curb JD, Pressel SL, Cutler JA, et al. Effect of diureticbased antihypertensive treatment on cardiovascular disease risk in older diabetic patients with isolated systolic hypertension. Systolic Hypertension in the Elderly Program Cooperative Research Group. JAMA 1996;276:1886-92.

44. Tight blood pressure control and risk of macrovascular and microvascular complications in type 2 diabetes: UKPDS 38. UK Prospective Diabetes Study Group. BMJ 1998:317:70313.

45. Cooper-DeHoff RM, Gong Y, Handberg EM, et al. Tight blood pressure control and cardiovascular outcomes among hypertensive patients with diabetes and coronary artery disease. JAMA 2010;304:61-8.
46. Sleight P, Redon J, Verdecchia P, et al. Prognostic value of blood pressure in patients with high vascular risk in the Ongoing Telmisartan Alone and in combination with Ramipril Global Endpoint Trial study. J Hypertens 2009;27:1360-9.

47. Baigent C, Keech A, Kearney PM, et al. Efficacy and safety of cholesterol-lowering treatment: prospective metaanalysis of data from 90,056 participants in 14 randomised trials of statins. Lancet 2005;366:1267-78.

48. Intensive blood-glucose control with sulphonylureas or insulin compared with conventional treatment and risk of complications in patients with type 2 diabetes (UKPDS 33). UK Prospective Diabetes Study (UKPDS) Group. Lancet 1998;352:837-53.

49. Holman RR, Paul SK, Bethel MA, Matthews DR, Neil HA. 10-year follow-up of intensive glucose control in type 2 diabetes. N Engl J Med 2008;359:1577-89.

50. Action to Control Cardiovascular Risk in Diabetes Study Group, Gerstein HC, Miller ME, Byington RP, et al. Effects of intensive glucose lowering in type 2 diabetes. $\mathrm{N}$ Engl J Med 2008;358:2545-59.

51. ADVANCE Collaborative Group, Patel A, MacMahon $\mathrm{S}$, Chalmers J, et al. Intensive blood glucose control and vascular outcomes in patients with type 2 diabetes. $\mathrm{N}$ Engl J Med 2008;358:2560-72.

52. Duckworth W, Abraira C, Moritz T, et al. Glucose control and vascular complications in veterans with type 2 diabetes. N Engl J Med 2009;360:129-39.

53. ACCORD Study Group, Gerstein HC, Miller ME, Genuth $\mathrm{S}$, et al. Long-term effects of intensive glucose lowering on cardiovascular outcomes. N Engl J Med 2011;364:818-28.

54. Ismail-Beigi F, Craven $\mathrm{T}$, Banerji MA, et al. Effect of intensive treatment of hyperglycaemia on microvascular outcomes in type 2 diabetes: an analysis of the ACCORD randomised trial. Lancet 2010;376:419-30.

55. ACCORD Study Group; ACCORD Eye Study Group, Chew EY, Ambrosius WT, Davis MD, et al. Effects of medical therapies on retinopathy progression in type 2 diabetes. $\mathrm{N}$ Engl J Med 2010;363:233-44.

56. Dorner B, Friedrich EK, Posthauer ME; American Dietetic Association. Position of the American Dietetic Association: individualized nutrition approaches for older adults in health care communities. J Am Diet Assoc 2010;110:154953.

57. Schafer RG, Bohannon B, Franz MJ, et al. Diabetes nutrition recommendations for health care institutions. Diabetes Care 2004;27 Suppl 1:S55-7.

58. American Diabetes Association, Bantle JP, Wylie-Rosett J, Albright AL, et al. Nutrition recommendations and interventions for diabetes: a position statement of the American Diabetes Association. Diabetes Care 2008;31 Suppl 1:S61-78. 